\title{
Impact of a Randomized Controlled Educational Trial to Improve Physician Practice Behaviors Around Screening for Inherited Breast Cancer
}

\author{
Robert A. Bell, $P h D^{7}$, Haley McDermott, MPH², Tonya L. Fancher, MD ${ }^{3}$, Michael J. Green, MD ${ }^{4}$, \\ Frank C. Day, MD, MPH ${ }^{5}$, and Michael S. Wilkes, MD, MPH, PhD ${ }^{6}$
}

'Department of Communication, Department of Public Health Sciences, University of California, Davis, Davis, CA, USA; ${ }^{2}$ School of Medicine, University of California, Davis, Davis, CA, USA; ${ }^{3}$ Department of Internal Medicine, Division of General Medicine, University of California, Davis, Sacramento, CA, USA; ${ }^{4}$ Departments of Humanities and Medicine, Penn State College of Medicine, Hershey, PA, USA; ${ }^{5}$ Department of Medicine, University of California, Los Angeles, Los Angeles, CA, USA; ${ }^{6}$ School of Medicine, Office of the Dean, University of California, Davis, Davis, CA, USA.

BACKGROUND: Many primary care physicians (PCPs) are ill-equipped to provide screening and counseling for inherited breast cancer.

OBJECTIVE: To evaluate the outcomes of an interactive web-based genetics curriculum versus text curriculum for primary care physicians.

DESIGN: Randomized two-group design.

PARTICIPANTS: 121 California and Pennsylvania community physicians.

INTERVENTION: Web-based interactive genetics curriculum, evaluated against a control group of physicians who studied genetics review articles. After education, physicians interacted with an announced standardized patient (SP) at risk for inherited breast cancer.

MAIN MEASURES: Transcripts of visit discussions were coded for presence or absence of 69 topics relevant to inherited breast cancer.

KEY RESULTS: Across all physicians, history-taking, discussions of test result implications, and exploration of ethical and legal issues were incomplete. Approximately half of physicians offered a genetic counseling referral (54.6\%), and fewer (43.8\%) recommended testing. Intervention physicians were more likely than controls to explore genetic counseling benefits (78.3 \% versus $60.7 \%, P=0.048$ ), encourage genetic counseling before testing (38.3\% versus $21.3 \%, P=$ 0.048), ask about a family history of prostate cancer (25.0\% versus $6.6 \%, P=0.006)$, and report that a positive result indicated an increased risk of prostate cancer for male relatives $(20.0 \%$ versus $1.6 \%, P=0.001)$. Intervention-group physicians were less likely than controls to ask about Ashkenazi heritage (13.3\% versus $34.4 \%, P=0.01$ ) or to reply that they would get tested when asked, "What would you do?" (33.3 \% versus $54.1 \%, P=0.03$ ).

CONCLUSIONS: Physicians infrequently performed key counseling behaviors, and this was true regardless of whether they had completed the web-based interactive training or read clinical reviews.

Received August 29, 2014

Revised October 14, 2014

Accepted November 5, 2014

Published online December 2, 2014
KEY WORDS: inherited breast cancer; physician training; BRCA; genetic counseling; genetic testing.

J Gen Intern Med 30(3):334-41

DOI: $10.1007 / \mathrm{s} 11606-014-3113-5$

(C) Society of General Internal Medicine 2014

\section{INTRODUCTION}

A BRCA mutation is present in about 1 in 400 women in the general population ${ }^{1}$; for these women, the average cumulative cancer risk by age 70 ranges from $45 \%$ to $65 \%$ for breast cancer and from $11 \%$ to $39 \%$ for ovarian cancer. Those with BRCA mutations account for $7 \%$ of all breast cancers and $10 \%$ to $15 \%$ of ovarian cancers. ${ }^{2,3}$ The discovery of links between BRCA mutations and breast cancer creates an opportunity to identify individuals at risk and to intervene early in the disease process. ${ }^{4}$

Knowing how to screen appropriately for genetic risk factors for breast cancer and when to offer genetic testing are core skills for primary care physicians (PCPs), especially given the relative scarcity of genetic counselors. ${ }^{5,6}$ Identification of women with genetic mutations allows for aggressive surveillance, risk-reduction interventions, and identification of family members who may also be at risk. ${ }^{7,8}$ Many PCPs have an inadequate understanding of hereditary breast cancer, risk assessment, shared decision-making, and legal and ethical issues, ${ }^{9,10}$ and this results in inappropriate testing: underuse of testing and genetic counseling referral for patients at high risk $^{9,11-18}$ and overuse for those at low risk. ${ }^{18}$

Various interventions aimed at increasing patient knowledge have been shown to be effective. ${ }^{19-25}$ That said, there are few educational interventions focusing on hereditary breast cancer that target physicians or trainees. ${ }^{26}$ Here, we report an evaluation of an interactive web-based genetics curriculum for PCPs using announced standardized patient (SP) visits. The SP approach provides insights into clinical behaviors not provided by physician and patient surveys. ${ }^{27}$ Physicians were not told that the SP visit would focus on breast cancer. Our primary research objective was to determine whether the educational intervention was more effective than a control 
curriculum at eliciting: 1) appropriate physician behaviors with regard to assessments of the patient's risk for hereditary breast cancer; 2) discussion of genetic testing and counseling; and 3) exploration of ethical, legal, and social issues (ELSI) surrounding genetic testing.

\section{METHODS}

\section{Setting and Participants}

The study took place in California (Los Angeles and the Greater Sacramento areas) and rural Pennsylvania. PCPs were eligible if they were an MD or DO, English-speaking, and had Internet and e-mail access. In California, a list of PCPs was compiled through an internet search. Physicians were then sent information about the study through faxes and flyers. Colleagues at clinics in two large health systems made recruitment appeals on our behalf. In Pennsylvania, PCPs were identified via the Pennsylvania Area Health Education Center, which sent personalized letters of invitation, recruitment flyers, and business reply postcards to prospective participants. The Pennsylvania State University (PSU) team sent recruitment materials to PCPs around the state. Across all sites, 121 PCPs were recruited between September 2011 and April 2013 (Fig. 1). Participants were offered six units of continuing medical education (CME) credit and a payment of $\$ 250$ after study completion; credit and payment were not affected by performance during the SP visit.

\section{Design and Procedure Overview}

Study procedures were IRB-approved in California and Pennsylvania. Each physician was randomly assigned to an intervention group $(n=60)$ or control group $(n=61)$. Upon enrollment, physicians participated in a pre-intervention objective structured video exercise (OSVE), responded to an online pre-visit questionnaire, completed the educational curriculum, took an online post-visit survey, and finally, completed a post-intervention OSVE. OSVEs provided no instruction on inherited breast cancer. After the curriculum had been completed, a time was scheduled for the SP visit. PCPs were

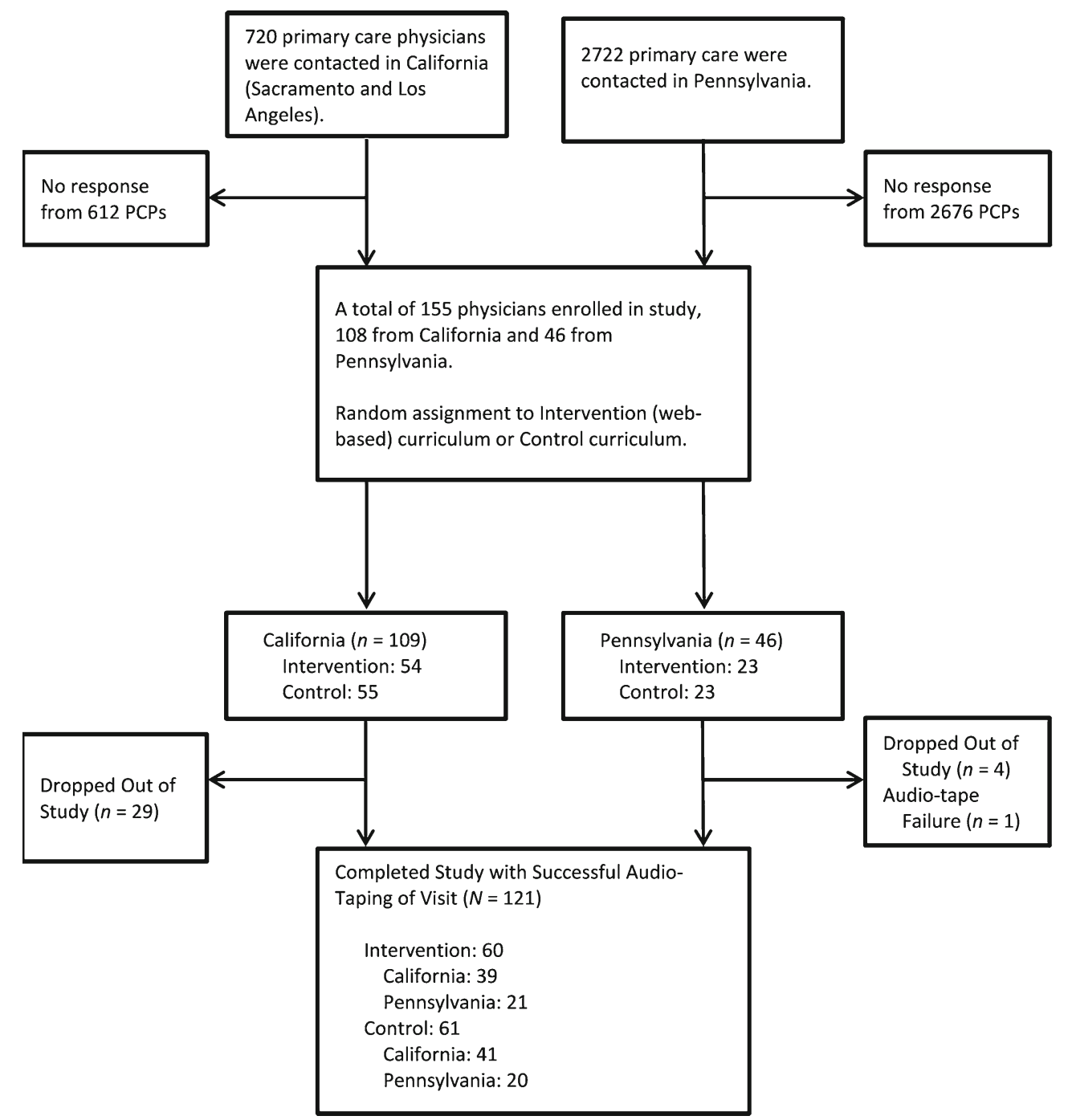

Fig. 1 Study flow diagram. 
told only that the SP would be used to evaluate the curriculum; no mention was made of the clinical condition (breast cancer). Visits took place an average of one month after completion of the curriculum. These visits were audio-taped, transcribed, and then coded.

\section{Intervention and Control Group Curricula}

Intervention Group. Intervention-group physicians completed a six-hour interactive web-based curriculum covering information about genetic testing, risk assessment, practice behaviors, and communication skills. The curriculum featured four clinical patient cases, with tutorials developed around specific learning objectives to illustrate common genetic conditions likely to be encountered by PCPs-breast cancer, cystic fibrosis, Huntington's Disease, and inherited thrombophilia. Each case included video vignettes that modeled physician communication, raised questions requiring application of principles, and provided hyperlinks to additional written and video materials. The tutorials included in-depth considerations of epidemiology and ELSI related to genetics. A more complete description of the technology underlying the intervention has been reported elsewhere. ${ }^{4}$ Essential competencies were derived from organizational recommendations, ${ }^{28}$ published reports, ${ }^{29}$ and the input of 20 expert consultants from six academic institutions. ${ }^{4}$ Because of resource limitations, just one of the four medical conditions, breast cancer, was addressed in the SP study described below.

Control Group. Control group participants read eight review articles from leading journals and an information sheet extracted from the National Cancer Institute website. ${ }^{30-38}$ These nine resources covered clinical genetics, ethical issues, doctor-patient issues, and clinical reasoning, and were topically similar to the material contained in the intervention group. Participant access and downloading of the articles was recorded electronically. It was estimated that physicians would need at least six hours to read all articles. The use of such a control group allowed us to examine the impact of our webbased curriculum relative to a more traditional learning format. Given the newness of the genetics information provided in the intervention, evaluating it against a control group of untaught physicians would have been a less meaningful comparison.

\section{Standardized Patient Procedure}

Each physician was visited by one of five actresses playing the role of "Catherine Douglas," a trained and rehearsed SP portraying a woman at risk for inherited breast cancer. For logistic reasons, SP visits were announced to the clinics in advance. Catherine arrived at the physician office with documents, purportedly prepared by her last physician from another state, describing her as a 41-year old, divorced, college-educated white woman with an unremarkable medical history other than intermittent headaches. She had a son (age 13) and daughter (age 17). She had just moved to the area to take care of her younger sister, who was recently diagnosed with breast cancer.

Catherine initiated the encounter with the following: " $M y$ sister was recently diagnosed with breast cancer. Although I am very concerned about her, I was wondering how much I have to worry about getting breast cancer myself." Though her mammogram was normal, she had read a story about genetic testing for breast cancer and would like to know more. If the physician asked about her family history, Catherine reported that her mother had been diagnosed with breast cancer at age 50, had a mastectomy, but died from the disease at age 52. If asked about other cancers in the family, the doctor would learn that Catherine's maternal aunt had died at age 40 of cancer - possibly ovarian cancer, but Catherine is uncertain. Answers to anticipated physician questions were scripted such that Catherine had a greater-than-average risk of breast cancer and would be a reasonable candidate for genetic counseling and testing.

\section{Coding of Physician Behavior}

One author (HD) coded transcripts of all visits, and a second (RB) independently coded 60 visits in order to assess coding reliability (average Cohen's kappa, 0.91). Coding consisted of a determination of the presence or absence of 69 specific physician behaviors pertaining to the SP's family history and personal health history, implications of genetic test results for the SP and her family, ELSI, genetic counseling, and genetic tests. These codes (described below) captured widely accepted core competencies. ${ }^{39,40}$

\section{Statistical Analysis}

Data were analyzed using Stata (version 12.1). Descriptive statistics were used to describe characteristics of the sample. Cross-tabulations were used to compare intervention and control groups on dichotomous behavioral outcomes. Fisher's exact test was used to test for statistical significance.

\section{RESULTS}

\section{Physician and Visit Characteristics}

Physicians were primarily male, white, non-Hispanic, and middle-aged (Table 1). The SP visit occurred an average of one month after completion of learning activities. There were no significant differences between the intervention and control groups with regard to demographics, years of practice, or experience with inherited breast cancer. Additionally, there were no significant interactions between region (CA versus PA) and study variables, allowing for aggregation of data across states. 
Table 1 Physician Characteristics by Study Group

\begin{tabular}{|c|c|c|c|c|}
\hline Characteristic & $\begin{array}{l}\text { Control } \\
(n=61)\end{array}$ & $\begin{array}{l}\text { Intervention } \\
(n=60)\end{array}$ & $\begin{array}{l}\text { Combined } \\
(n=121)\end{array}$ & $P^{*}$ \\
\hline Age, mean (SD) & $\begin{array}{l}48.7 \\
(9.8)\end{array}$ & $49.1(10.6)$ & $48.9(10.1)$ & 0.81 \\
\hline $\begin{array}{l}\text { Years since MD, } \\
\text { mean (SD) }\end{array}$ & $\begin{array}{l}21.7 \\
(9.7)\end{array}$ & $21.3(12.3)$ & $21.5(11.0)$ & 0.86 \\
\hline Female, $\%$ & 34.4 & 46.7 & 40.5 & 0.20 \\
\hline White race, $\%$ & 67.2 & 70.0 & 68.6 & 0.85 \\
\hline Hispanic, $\%$ & 4.9 & 8.3 & 6.6 & 0.49 \\
\hline $\begin{array}{l}\text { Experience, either in } \\
\text { physician practice or } \\
\text { personally, with } \\
\text { inherited breast } \\
\text { cancer, \% }\end{array}$ & 49.2 & 53.3 & 51.2 & 0.72 \\
\hline
\end{tabular}

* The significance of mean differences between study groups were examined with $t$ tests. Differences for the categorical demographic and experience variables were examined with Fisher's exact test. Nonsignificant differences are suggestive of successful randomization of participants to the two study arms.

\section{Clinical Behaviors}

History-Taking. The number (and percentage) of physicians who asked about each of 10 family issues is reported in the top section of Table 2. Physicians asked an average of 2.2 $(\mathrm{SD}=1.5)$ questions relating to the family history issues listed in the table. For only one topic (SP's mother's age at onset of breast cancer) did more than $50 \%$ of physicians ascertain information. Specific questions about cancers in the family, including ovarian, breast, and prostate cancers, were not usually asked. Significant differences were found between physicians in the control and intervention groups on two family history variables. Intervention-group participants were more likely than control physicians to ask about a history of prostate cancer among relatives, but were less likely to ask about Ashkenazi Jewish heritage.

Queries about the SP's personal history are reported in the bottom section of Table 2. Physicians asked an average of 2.0 $(\mathrm{SD}=1.5)$ of these 11 personal history questions. More than two-thirds asked the SP about her age and whether she underwent regular mammography screening. All other personal history queries were made in less than $16 \%$ of visits. There were no significant differences between intervention and control-group learners on any of the personal history-taking queries.

Discussions About Implications of Test Results. Counseling on test result implications for the SP are reported in Table 3. Intervention and control-group physicians did not differ significantly on any of these counseling behaviors. Physicians discussed an average of $5.2(\mathrm{SD}=1.8)$ of the 13 topics reported in the table. A majority of physicians informed the SP that a positive test result points to an increased risk of developing breast or ovarian cancer. With regard to treatment implications of a positive result, most physicians emphasized that such results would lead to a consideration of surgical options. Other implications of treatment were discussed by about one-fourth or less of the physicians. The third section of the table reports that most physicians counseled the SP about the implications of a positive result regarding ongoing screening, but few discussed what such a test result would mean for selfmonitoring with breast exams. In the fourth section of Table 3, it is shown that the limitations of current genetic testing received very little attention. The last section of the table

Table 2 Physician History-Taking Queries, Sorted by Combined Frequency of Occurrence*

\begin{tabular}{|c|c|c|c|c|}
\hline Topic & $\begin{array}{l}\text { Control } \\
(n=61)\end{array}$ & $\begin{array}{l}\text { Intervention } \\
(n=60)\end{array}$ & $\begin{array}{l}\text { Combined } \\
(n=121)\end{array}$ & $P \dagger$ \\
\hline \multicolumn{5}{|l|}{ SP’s family history } \\
\hline Mother's age at onset of breast cancer & $34(55.7 \%)$ & $34(56.8 \%)$ & $68(56.2 \%)$ & 1.0 \\
\hline Other cancers in family & $29(47.5 \%)$ & $21(35.0 \%)$ & $50(41.3 \%)$ & 0.20 \\
\hline Any relative with ovarian cancer diagnosis & $22(36.1 \%)$ & $20(33.3 \%)$ & $42(34.7 \%)$ & 0.85 \\
\hline Second-degree relative $\mathrm{w} /$ breast cancer & $21(34.4 \%)$ & $16(26.7 \%)$ & $37(30.6 \%)$ & 0.43 \\
\hline Ashkenazi Jewish heritage & $21(34.4 \%)$ & $8(13.3 \%)$ & $29(24.0 \%)$ & 0.01 \\
\hline Any male relative $\mathrm{w} /$ prostate cancer & $4(6.6 \%)$ & $15(25.0 \%)$ & $19(15.7 \%)$ & 0.006 \\
\hline Was mother's breast cancer bilateral & $4(6.6 \%)$ & $4(6.7 \%)$ & $8(6.6 \%)$ & 1.0 \\
\hline Was sister's breast cancer bilateral & $3(4.9 \%)$ & $4(6.7 \%)$ & $7(5.8 \%)$ & 0.72 \\
\hline Third-degree relative with breast cancer & $5(8.2 \%)$ & $1(1.7 \%)$ & $6(5.0 \%)$ & 0.21 \\
\hline Any male relative $\mathrm{w} /$ breast cancer & $3(4.9 \%)$ & $2(3.3 \%)$ & $5(4.1 \%)$ & 1.0 \\
\hline \multicolumn{5}{|l|}{ SP's personal history } \\
\hline Regular mammography & $45(73.8 \%)$ & $46(76.7 \%)$ & $91(75.2 \%)$ & 0.83 \\
\hline Current age & $43(70.5 \%)$ & $40(66.7 \%)$ & $83(68.6 \%)$ & 0.70 \\
\hline Current or past use of oral contraceptive pills & $11(18.0 \%)$ & $8(13.3 \%)$ & $19(15.7 \%)$ & 0.62 \\
\hline Lifetime no. of pregnancies & $9(14.8 \%)$ & $8(13.3 \%)$ & $17(14.1 \%)$ & 1.0 \\
\hline Regular intake of alcohol & $7(11.5 \%)$ & $5(8.3 \%)$ & $12(9.9 \%)$ & 0.76 \\
\hline Breastfeeding of children & $4(6.6 \%)$ & $4(6.7 \%)$ & $8(6.6 \%)$ & 1.0 \\
\hline Age at first live birth & $3(4.9 \%)$ & $2(3.3 \%)$ & $5(4.1 \%)$ & 1.0 \\
\hline Weight/BMI & $2(3.3 \%)$ & $1(1.7 \%)$ & $3(2.5 \%)$ & 1.0 \\
\hline Past breast biopsy & $2(3.3 \%)$ & $1(1.7 \%)$ & $3(2.5 \%)$ & 1.0 \\
\hline Age at first menstrual period & $2(3.3 \%)$ & $0(0.0 \%)$ & $2(1.7 \%)$ & 0.50 \\
\hline Current or past hormone replacement therapy & $2(3.3 \%)$ & $0(0.0 \%)$ & $2(1.7 \%)$ & 0.50 \\
\hline
\end{tabular}

*Values reported are the numbers (percentages) of physicians who made the query during the visit

†Probability values are based on Fisher's exact test

tQueries about the cancer history of the SP's mother and sister were not coded because this information was volunteered by the SP as part of the standardized script 
Table 3 Physician Counseling About Test Result Implications for the SP, Sorted by Combined Frequency of Occurrence*

\begin{tabular}{|c|c|c|c|c|}
\hline Topic & $\begin{array}{l}\text { Control } \\
(n=61)\end{array}$ & $\begin{array}{l}\text { Intervention } \\
(n=60)\end{array}$ & $\begin{array}{l}\text { Combined } \\
(n=121)\end{array}$ & $P \dagger$ \\
\hline \multicolumn{5}{|l|}{ Cancer risks } \\
\hline Positive result means increased risk of breast cancer & $45(73.8 \%)$ & $43(71.7 \%)$ & $88(72.3 \%)$ & 0.84 \\
\hline Positive result means increased risk of ovarian cancer & $38(62.3 \%)$ & $32(53.3 \%)$ & $70(57.9 \%)$ & 0.36 \\
\hline \multicolumn{5}{|l|}{ Treatment implications } \\
\hline Positive result introduces option of surgical treatment & $57(93.4 \%)$ & $55(91.7 \%)$ & $112(92.6 \%)$ & 0.74 \\
\hline $\begin{array}{l}\text { Positive result has fertility implications due to effects of prophylactic treatments } \\
\text { (oophorectomy) }\end{array}$ & $13(21.3 \%)$ & $19(31.7 \%)$ & $32(26.5 \%)$ & 0.22 \\
\hline Positive result introduces option of prophylaxis with medications & $19(31.2 \%)$ & $11(18.3 \%)$ & $30(24.8 \%)$ & 0.14 \\
\hline \multicolumn{5}{|l|}{ Screening implications } \\
\hline Positive result means more ongoing testing/screening & $49(80.3 \%)$ & $52(86.7 \%)$ & $101(83.5 \%)$ & 0.46 \\
\hline Positive result underscores the importance of self-monitoring with breast exams & $6(9.8 \%)$ & $5(8.3 \%)$ & $11(9.1 \%)$ & 1.0 \\
\hline \multicolumn{5}{|l|}{ Test limitations } \\
\hline Even with negative result, SP (and/or sister) could still get breast cancer & $21(34.4 \%)$ & $17(28.3 \%)$ & $38(31.4 \%)$ & 0.56 \\
\hline Tests only look for known mutations & $15(24.6 \%)$ & $17(28.3 \%)$ & $32(26.5 \%)$ & 0.68 \\
\hline Genetic testing is not $100 \%$ accurate & $8(13.1 \%)$ & $4(6.7 \%)$ & $12(9.9 \%)$ & 0.36 \\
\hline \multicolumn{5}{|l|}{ Emotional issues } \\
\hline Physician discusses emotional repercussions of testing for SP & $27(44.3 \%)$ & $30(50.0 \%)$ & $57(47.1 \%)$ & 0.59 \\
\hline $\begin{array}{l}\text { Physician discusses how a negative test result could be beneficial to } \\
\text { the SP (e.g., reassurance) }\end{array}$ & $23(37.7 \%)$ & $19(31.7 \%)$ & $42(34.7 \%)$ & 0.57 \\
\hline Physician asks if SP has support system (in relation to BRCA testing) & $2(3.3 \%)$ & $3(5.0 \%)$ & $5(4.1 \%)$ & 0.68 \\
\hline
\end{tabular}

† Probability values are based on Fisher's exact test.

reports that the emotional repercussions of genetic testing for the SP were explored by nearly half of physicians. The potential benefits of receiving a negative test result were discussed by approximately one-third of physicians. Rarely did the physician ask about the SP's support system.

Implications of Testing for the SP's Family. Genetic test results have implications for a patient's relatives. Physician counseling on such implications are reported in Table 4. On average, physicians covered $1.9(\mathrm{SD}=1.6)$ of the eight topics reported in the table. Only one significant difference between groups was found. Intervention-group physicians were more likely than control physicians to tell the SP that if she tested positive, it would indicate that her male relatives were at greater risk of prostate cancer. With regard to relatives' cancer risks, a majority of physicians discussed the daughter's elevated risk of cancer. Physician counseling on what a positive test result would mean for the genetic testing of other family members was rarely offered. Physicians rarely mentioned that a positive test result could necessitate breast cancer screening and possibly surgery or prophylaxis with medications for other family members. The emotional impact on the family of a positive test result for the SP was seldom discussed.

Discussions About Genetic Counseling. The frequency of discussions about counseling and testing are reported in Table 5. Most physicians discussed the benefits of genetic counseling, but intervention-group physicians were significantly more likely to do this than control-group physicians. A majority of physicians offered a referral to a genetic counselor. Cost issues related to testing were not typically discussed with the SP, and did not differ by study group. Genetic testing recommendations varied. The most common recommendation was that the SP should delay her testing

Table 4 Physician Counseling About Test Result Implications for the SP's Family Members, Sorted by Combined Frequency of Occurrence*

\begin{tabular}{|c|c|c|c|c|}
\hline Topic & $\begin{array}{l}\text { Control } \\
(n=61)\end{array}$ & $\begin{array}{l}\text { Intervention } \\
(n=60)\end{array}$ & $\begin{array}{l}\text { Combined } \\
(n=121)\end{array}$ & $P \dagger$ \\
\hline \multicolumn{5}{|l|}{ Family cancer risks } \\
\hline Positive result means daughter is at increased risk of cancer & $35(57.4 \%)$ & $33(55.0 \%)$ & $68(56.2 \%)$ & 0.86 \\
\hline Positive result means son is at increased risk of cancer & $14(23.0 \%)$ & $21(35.0 \%)$ & $35(28.9 \%)$ & 0.16 \\
\hline Positive result means increased risk of prostate cancer for male relatives & $1(1.6 \%)$ & $12(20.0 \%)$ & $13(10.7 \%)$ & .001 \\
\hline \multicolumn{5}{|l|}{ Genetic testing } \\
\hline $\begin{array}{l}\text { Positive result means female family members } \\
\text { (in addition to the sister) may need genetic testing }\end{array}$ & $28(49.5 \%)$ & $24(40.0 \%)$ & $52(43.0 \%)$ & 0.58 \\
\hline Positive result means male family members may need genetic testing & $7(11.5 \%)$ & $6(10.0 \%)$ & $13(10.7 \%)$ & 1.0 \\
\hline \multicolumn{5}{|l|}{ Screening and treatment } \\
\hline Positive result means family members may need additional breast cancer screening & $12(19.7 \%)$ & $9(15.0 \%)$ & $21(17.4 \%)$ & 0.63 \\
\hline $\begin{array}{l}\text { Positive result means family members may need treatment } \\
\text { (including surgery and prophylaxis with medications) }\end{array}$ & $7(11.5 \%)$ & $3(5.0 \%)$ & $10(8.3 \%)$ & 0.32 \\
\hline \multicolumn{5}{|l|}{ Emotional issues } \\
\hline Testing creates potential for emotional repercussions for the family & $12(19.7 \%)$ & $9(15.0 \%)$ & $21(17.4 \%)$ & 0.63 \\
\hline
\end{tabular}

* Values reported are the numbers (percentages) of physicians who raised the topic during the visit.

† Probability values are based on Fisher's exact test. 
Table 5 Physician Discussion and Recommendations Regarding Genetic Counseling, Genetic Tests, and ELSI, Sorted by Combined Frequency of Occurrence*

\begin{tabular}{|c|c|c|c|c|}
\hline Topic & $\begin{array}{l}\text { Control } \\
(n=61)\end{array}$ & $\begin{array}{l}\text { Intervention } \\
(n=60)\end{array}$ & $\begin{array}{l}\text { Combined } \\
(n=121)\end{array}$ & $P \dagger$ \\
\hline \multicolumn{5}{|l|}{ Benefits and referral } \\
\hline Benefits of genetic counseling & $37(60.7 \%)$ & $47(78.3 \%)$ & $84(69.4 \%)$ & 0.05 \\
\hline \multirow{2}{*}{\multicolumn{5}{|c|}{ Cost discussions }} \\
\hline & & & & \\
\hline Insurance coverage for testing & $22(36.1 \%)$ & $18(30.0 \%)$ & $40(33.1 \%)$ & 0.56 \\
\hline Cost of office genetic test & $16(26.2 \%)$ & $19(31.7 \%)$ & $35(28.9 \%)$ & 0.55 \\
\hline Cost of genetic counseling (including insurance coverage) & $3(4.9 \%)$ & $5(8.3 \%)$ & $8(6.6 \%)$ & 0.49 \\
\hline \multicolumn{5}{|l|}{ Testing recommendations } \\
\hline Sister should be tested first before SP makes a testing decision & $23(37.7 \%)$ & $33(55.0 \%)$ & $56(46.3 \%)$ & 0.07 \\
\hline SP should "think about it" and then revisit the physician & $22(36.1 \%)$ & $16(26.7 \%)$ & $38(31.4 \%)$ & 0.33 \\
\hline SP should make testing decision after genetic counseling visit & $13(21.3 \%)$ & $23(38.3 \%)$ & $36(29.8 \%)$ & 0.05 \\
\hline \multicolumn{5}{|l|}{ Testing expectations and concerns } \\
\hline Asks what SP would do if she received a positive BRCA test result & $27(44.3 \%)$ & $32(53.3 \%)$ & $59(48.8 \%)$ & 0.37 \\
\hline Asks the SP for her expectations for screening and/or today's visit & $9(14.8 \%)$ & $14(23.3 \%)$ & $23(19.0 \%)$ & 0.26 \\
\hline Asks how SP would feel if she received a positive BRCA test result & $4(6.6 \%)$ & $10(16.7 \%)$ & $14(11.6 \%)$ & 0.10 \\
\hline \multicolumn{5}{|l|}{ Response to, "what would you do?" $\$$} \\
\hline I would get tested & $33(54.1 \%)$ & $20(33.3 \%)$ & $53(43.8 \%)$ & 0.03 \\
\hline It's up to you. / Only you can decide. & $14(23.0 \%)$ & $24(40.0 \%)$ & $38(31.4 \%)$ & 0.052 \\
\hline I don't know & $2(3.3 \%)$ & $5(8.3 \%)$ & $7(5.8 \%)$ & 0.27 \\
\hline \multirow{2}{*}{\multicolumn{5}{|c|}{ ELSI for the SP }} \\
\hline & & & & \\
\hline Confidentiality of the medical record & $31(50.9 \%)$ & $34(56.7 \%)$ & $65(53.7 \%)$ & 0.59 \\
\hline Health insurance discrimination & $32(52.5 \%)$ & $32(53.3 \%)$ & $64(52.9 \%)$ & 1.0 \\
\hline Federal legal protections (GINA) & $35(57.4 \%)$ & $26(43.3 \%)$ & $61(50.4 \%)$ & 0.15 \\
\hline Life insurance discrimination & $30(49.2 \%)$ & $30(50.0 \%)$ & $60(49.6 \%)$ & 1.0 \\
\hline Employment discrimination & $11(18.0 \%)$ & $9(15.0 \%)$ & $20(16.5 \%)$ & 0.82 \\
\hline Stigma as a social issue & $0(0.0 \%)$ & $0(0.0 \%)$ & $0(0.0 \%)$ & - \\
\hline \multicolumn{5}{|l|}{ ELSI for family members } \\
\hline Life insurance discrimination & $1(1.6 \%)$ & $1(1.7 \%)$ & $2(1.7 \%)$ & 1.0 \\
\hline Health insurance discrimination & $1(1.6 \%)$ & $0(0.0 \%)$ & $1(0.8 \%)$ & 1.0 \\
\hline Confidentiality of the medical record & $1(1.6 \%)$ & $0(0.0 \%)$ & $1(0.8 \%)$ & 1.0 \\
\hline Employment discrimination & $0(0.0 \%)$ & $0(0.0 \%)$ & $0(0.0 \%)$ & - \\
\hline Federal legal protections (GINA) & $0(0.0 \%)$ & $0(0.0 \%)$ & $0(0.0 \%)$ & - \\
\hline Stigma as a social issue & $0(0.0 \%)$ & $0(0.0 \%)$ & $0(0.0 \%)$ & - \\
\hline
\end{tabular}

ELSI ethical, legal, and social issues

+ Probability values are based on Fisher's exact test.

$\$$ Numbers for this grouping need not sum to $100 \%$. A physician could ignore the query or respond in a manner not represented by our codes.

decision until after her sister had been tested. Intervention physicians were significantly more likely than control physicians to advise making a testing decision after counseling. Fewer than one in five physicians asked the SP about her expectations for cancer screening and for the visit. Nearly half of physicians asked the SP what she would $d o$ if she received a positive test result, but the SP was asked how she would feel in such an event in only one-tenth of visits.

As part of the standardized script, physicians were asked if they would get the test "if you were me." Intervention-group physicians were less likely than control-group physicians to respond that they would be tested, and were more inclined to tell the SP that she needed to decide what was best for her. This difference narrowly failed to reach conventional standards of statistical significance. Physicians rarely said that they did not know what they would do if placed in the SP's position or that they would not get tested.

Ethical, Legal, and Social Issues. Coded topics pertaining to the relevance of ethical, legal, and social issues for the patient are shown in the sixth section of Table 5; there was no difference between intervention and control groups. The most frequently discussed ELSI issue was medical record confidentiality, followed by health insurance discrimination issues, Genetic Information Nondiscrimination Act (GINA) legislation, and life insurance discrimination. Employment discrimination was rarely discussed, and the potential for social stigma stemming from a positive test result was not considered in any visit. The last section of the table reports how often these same issues were discussed with regard to the impact of the SP's test result on other family members. Such discussions were absent in virtually all visits.

\section{DISCUSSION}

An increasing number of genetic tests are available that can identify carriers of mutations that elevate cancer risk, such as BRCA. ${ }^{10}$ Many patients with questions about their risks seek answers from their PCPs ${ }^{41}$ underscoring the need for clinical genetics education in primary care. This study evaluated the 
effectiveness of one such training program - an interactive webbased curriculum delivered as CME. The intervention's impact on practice behaviors was minimal, with a few notable exceptions.

Intervention-group physicians were more likely to inform patients that a test showing a BRCA mutation could indicate an increased risk for prostate cancer among relatives. However, they were less likely than controls to ask about Ashkenazi heritage, even though the link between Ashkenazi heritage and breast cancer has been known and taught for many years. Intervention-group physicians were also more likely than controls to explore the benefits of genetic counseling and to encourage a deferral of the testing decision until after genetic counseling. They were not more likely than control physicians, however, to offer genetic counseling to the SP.

In an era of increasingly complex and numerous genetic tests, PCPs may lack the time and expertise to provide the specialized counseling that a trained genetic counselor can offer. Modifying the online curriculum to facilitate appropriate referrals may help to ensure that patients receive the information they need to make informed choices. When asked what they would do if personally faced with a similar situation, intervention-group physicians were more inclined than control-group physicians to engage in a nuanced discussion around values and goals. This greater appreciation of contingent decision-making and respect for the patient's values may flow from the intervention curriculum's modeling of shared decision-making.

Regardless of the curriculum completed, participants were generally unprepared to provide robust counseling to an SP for whom genetic counseling and genetic testing was reasonable. The average physician in this study asked just $20 \%$ of the family and personal history questions that would be appropriate in this setting, a finding consistent with other studies. ${ }^{11,27}$ Physicians also fell short in their counseling about the implications of test results, focusing heavily on surgical options and neglecting to explore familial implications, emotional impacts, or social support, though each of these is an essential component of the genetic counseling process. ${ }^{42-45}$

Furthermore, though considerable attention was devoted to ELSI issues in the web-based and control curriculum materials, only half of the participants talked with the SP about medical record confidentiality, insurance discrimination, and federal legal protections. Even fewer examined employment discrimination concerns, and none explored the important issue of social stigma. ${ }^{43}$ These ELSI discussions rarely examined the potential for discrimination against family members that could result from a positive BRCA test result or legal protections for the patient or their family.

In light of these findings, clinical genetics training may need to be longer and periodically reinforced. Alternatively, it may be unrealistic to expect PCPs to provide necessary information to patients presenting with concerns about their inherited risk for cancer. Genetic counselors are specialtytrained to have these conversations and typically have more time and resources to discuss these matters than do PCPs.
Though computer-based curricula aimed at educating patients have been shown to be effective at increasing knowledge about genetic testing for inherited breast cancer, ${ }^{46,47}$ educating time-constrained physicians is challenging, and perhaps our goals should shift toward increasing availability of and referrals to genetic counselors.

\section{Limitations}

A large number of physicians invited to participate did not respond to the invitation, leading to the possibility of a selection bias wherein motivated and interested physicians were overrepresented. The effect of such a selection bias would be to overstate the true level of provider ability in the domain studied. The SPs were announced, and although physicians had no advanced knowledge of the clinical presentation, they did know that they were being evaluated. They may, therefore, have exhibited a higher level of clinical skills than would have been observed had the SPs been unannounced. ${ }^{48}$ Further, we examined just one genetic condition; findings may not generalize to other conditions. Finally, the study was carried out in only two states.

\section{CONCLUSIONS}

Physicians infrequently performed key counseling behaviors surrounding inherited breast cancer, and this was true regardless of whether they had completed the web-based interactive training or read clinical reviews. Ultimately, we may conclude that the promise of the clinical genetics revolution can be realized only by preparing current and future primary care physicians to identify patients at risk for inherited conditions and to refer those patients for appropriate counseling and testing.

Contributors: We are grateful to the following individuals for their contributions to our study: Julie Anchor, Ryan Angel, Claudia DerMartirosian, Paul Drummond, Andy Fanning, Laurie Gunderman, Christine Harlan, Stacy Hayashi, Jody McCullough, Dan Plummer, Kelly Serafini, Andrea Shreeman, and Ruby Sketchley.

Funders: This research was supported by National Human Genome Research Institute grant 5-R01-HG005117 (M.S. Wilkes, PI).

Prior Presentations: None.

Conflicts of Interest: The authors each declare that they have no conflict of interest to report.

Corresponding Author: Robert A. Bell, PhD; Department of Communication, Department of Public Health SciencesUniversity of California, Davis, One Shields Avenue, Davis, CA 95616, USA (e-mail: rabell@ucdavis.edu).

\section{REFERENCES}

1. Whittemore AS, Gong G, John EM, McGuire V, Li FP, Ostrow KL, et al. Prevalence of BRCA1 mutation carriers among U.S. non-Hispanic Whites. Cancer Epidemiol Biomarkers Prev. 2004;13(12):2078-83.

2. Pal T, Permuth-Wey J, Betts JA, Krischer JP, Fiorica J, Arango H, et al. BRCA1 and BRCA2 mutations account for a large proportion of ovarian carcinoma cases. Cancer. 2005;104(12):2807-16. 
3. Claus EB, Schildkraut JM, Thompson WD, Risch NJ. The genetic attributable risk of breast and ovarian cancer. Cancer. 1996;77(11):231824.

4. Srinivasan M, Day FC, Griffin E, Tancredi DJ, Burke W, Pinsky L, et al. Implementation outcomes of a multiinstitutional web-based ethical, legal, and social implications genetics curriculum for primary care residents in three specialties. Genet Med. 2011;13(6):553-62.

5. Moyer VA. Risk assessment, genetic counseling, and genetic testing for BRCA-related cancer in women: U.S. Preventive Services Task Force Recommendation Statement. Ann Intern Med. 2014;160(4).

6. Birch PH. Interactive e-counselling for genetics pre-test decisions: where are we now? Clin Genet. 2014.

7. Dhar SU, Cooper HP, Wang T, Parks B, Staggs SA, Hilsenbeck S, et al. Significant differences among physician specialties in management recommendations of BRCAl mutation carriers. Breast Cancer Res Treat. 2011;129(1):221-7

8. Daly MB, Axilbund JE, Buys S, Crawford B, Farrell CD, Friedman S, et al. Genetic/familial high-risk assessment: breast and ovarian. J Natl Compr Cancer Netw. 2010;8(5):562-94.

9. Pal T, Cragun D, Lewis C, Doty A, Rodriguez M, Radford C, et al. A statewide survey of practitioners to assess knowledge and clinical practices regarding hereditary breast and ovarian cancer. Genet Test Mol Biomark. 2013; 17(5):367-75.

10. Culver JO, Bowen DJ, Reynolds SE, Pinsky LE, Press N, Burke W. Breast cancer risk communication: assessment of primary care physicians by standardized patients. Genet Med. 2009;11(10):735-41.

11. Bellcross CA, Kolor K, Goddard KA, Coates RJ, Reyes M, Khoury MJ. Awareness and utilization of BRCAl/2 testing among U.S. primary care physicians. Am J Prev Med. 2011;40(1):61-6.

12. Baer HJ, Brawarsky P, Murray MF, Haas JS. Familial risk of cancer and knowledge and use of genetic testing. J Gen Intern Med. 2010;25(7):71724.

13. Olaya W, Esquivel P, Wong JH, Morgan JW, Freeberg A, RoyChowdhury S, et al. Disparities in BRCA testing: when insurance coverage is not a barrier. Am J Surg. 2009; 198(4):562-5.

14. Guillin JM, Krist AH, Gyure M, Corona R, Rodriguez V, Borzelleca J, et al. Patient-reported hereditary breast and ovarian cancer in a primary care practice. J Community Genet. 2014;5(2):179-83.

15. Thompson HS, Sussner $\mathbf{K}$, Schwartz MD, Edwards T, Forman A, Jandorf $\mathbf{L}$, et al. Receipt of genetic counseling recommendations among black women at high risk for BRCA mutations. Genet Test Mol Biomark. 2012; 16(11): 1257-62.

16. Bellcross CA, Leadbetter S, Alford SH, Peipins LA. Prevalence and healthcare actions of women in a large health system with a family history meeting the 2005 USPSTF recommendation for BRCA genetic counseling referral. Cancer Epidemiol Biomarkers Prev. 2013;22(4):728-35.

17. Stuckey A, Febbraro T, Laprise J, Wilbur JS, Lopes V, Robison K. Adherence patterns to National Comprehensive Cancer Network Guidelines for referral of women with breast cancer to genetics professionals. Am J Clin Oncol. 2014.

18. Trivers KF, Baldwin LM, Miller JW, Matthews B, Andrilla CH, Lishner DM, et al. Reported referral for genetic counseling or BRCA $1 / 2$ testing among United States physicians: a vignette-based study. Cancer. 2011;117(23):5334-43.

19. Appleton S, Watson M, Rush R, Garcia-Minaur S, Porteous M, Campbell $\mathbf{J}$, et al. A randomised controlled trial of a psychoeducational intervention for women at increased risk of breast cancer. Br J Cancer. 2004;90(1):417.

20. Cull A, Miller H, Porterfield T, Mackay J, Anderson ED, Steel CM, et al. The use of videotaped information in cancer genetic counselling: a randomized evaluation study. Br J Cancer. 1998;77(5):830-7.

21. Mancini J, Noguès C, Adenis C, Berthet P, Bonadona V, Chompret A, et al. Impact of an information booklet on satisfaction and decision making about BRCA genetic testing. Eur J Cancer. 2006;42(7):871-81.

22. Schwartz MD, Benkendorf J, Lerman C, Isaacs C, Ryan-Robertson A, Johnson L. Impact of educational print materials on knowledge, attitudes, and interest in BRCA1/BRCA2: testing among Ashkenazi Jewish women. Cancer. 2001;92(4):932-40.

23. Skinner CS, Schildkraut JM, Berry D, Calingaert B, Marcom PK, Sugarman $\mathbf{J}$, et al. Pre-counseling education materials for BRCA testing: does tailoring make a difference? Genet Test. 2002;6(2):93105.

24. van Roosmalen MS, Stalmeier PF, Verhoef LC, Hoekstra-Weebers JE, Oosterwijk JC, Hoogerbrugge N, et al. Randomised trial of a decision aid and its timing for women being tested for a BRCAl/2 mutation. Br J Cancer. 2004;90(2):333-42.

25. Wolfe CR, Reyna VF, Widmer CL, Cedillos EM, Fisher CR, Brust-Renck PG, et al. Efficacy of a web-based intelligent tutoring system for communicating genetic risk of breast cancer: a fuzzy-trace theory approach. Med Decis Making. 2014.

26. Rupert DJ, Squiers LB, Renaud JM, Whitehead NS, Osborn RJ, Furberg RD, et al. Communicating risk of hereditary breast and ovarian cancer with an interactive decision support tool. Patient Educ Couns. 2013;92(2):188-96.

27. Burke W, Culver J, Pinsky L, Hall S, Reynolds SE, Yasui Y, et al. Genetic assessment of breast cancer risk in primary care practice. Am J Med Genet A. 2009;149A(3):349-56.

28. Collins FS, McInerney JD. Core competencies in genetics for health professionals. 3rd ed. Lutherville, MD: National Coalition for Health Professional Education in Genetics; 2007.

29. Burke W, Emery J. Genetics education for primary-care providers. Nat Rev Genet. 2002;3(7):561-6.

30. American College of Obstetricians and Gynecologists. ACOG Practice Bulletin No. 103: hereditary breast and ovarian cancer syndrome. Obstet Gynecol. 2009;113(4):957-66.

31. Anderson JA, Weitz JI. Hypercoagulable states. Clin Chest Med. 2010;31(4):659-73.

32. Dungan JS. Carrier screening for cystic fibrosis. Obstet Gynecol Clin N Am. 2010;37(1):47-59. Table of Contents.

33. Fowler FJ Jr, Levin CA, Sepucha KR. Informing and involving patients to improve the quality of medical decisions. Health Aff (Millwood). 2011;30(4):699-706.

34. Guttmacher AE, Collins FS. Genomic medicine-a primer. N Engl J Med. 2002;347(19): 1512-20.

35. Martin JR, Wilikofsky AS. Genetic counseling in primary care: longitudinal, psychosocial issues in genetic diagnosis and counseling. Prim Care. 2004;31(3):509-24. viii-ix

36. National Cancer Institute. 2010; Pages. Accessed at National Cancer Institute at http://www.cancer.gov/cancertopics/pdq/genetics/risk-assessment-and-counseling/HealthProfessional/ on November 5, 2014

37. Novak MJ, Tabrizi SJ. Huntington's disease. BMJ. 2010;340:c3109.

38. Sokol DK. Truth-telling in the doctor-patient relationship: a case analysis. Clin Ethics. 2006;1(3):1-5.

39. National Coalition for Health Professional Education in Genetics. Core competencies for all health professionals. 3rd ed. Lutherville, MD: NCHPEG; 2007. http://www.nchpeg.org/index.php?option=com content\&view=article\&id=237\&Itemid $=84$.

40. Amir E, Freedman OC, Seruga B, Evans DG. Assessing women at high risk of breast cancer: a review of risk assessment models. J Natl Cancer Inst. 2010;102(10):680-91.

41. Hoffman RM, Lewis CL, Pignone MP, Couper MP, Barry MJ, Elmore JG, et al. Decision-making processes for breast, colorectal, and prostate cancer screening: the DECISIONS survey. Med Dec Making. 2010;30(5 Suppl):53S-64S.

42. Cukier YR, Thompson HS, Sussner K, Forman A, Jandorf L, Edwards T, et al. Factors associated with psychological distress among women of African descent at high risk for BRCA mutations. J Genet Couns. 2013;22(1):101-7

43. Jabaley Leonarczyk T, Mawn BE. Cancer risk management decision making for BRCA+women. West J Nurs Res. 2014

44. Kegelaers D, Merckx W, Odeurs P, van den Ende J, Blaumeiser B. Disclosure pattern and follow-up after the molecular diagnosis of BRCA/ CHEK2 mutations. J Genet Couns. 2014;23(2):254-61.

45. Vadaparampil ST, Malo T, de la Cruz C, Christie J. Do breast cancer patients tested in the oncology care setting share BRCA mutation results with family members and health care providers? J Cancer Epidemiol. 2012;2012:498062.

46. Green MJ, Biesecker BB, McInerney AM, Mauger D, Fost N. An interactive computer program can effectively educate patients about genetic testing for breast cancer susceptibility. Am J Med Genet. 2001;103(1):16-23.

47. Green MJ, Peterson SK, Baker MW, Harper GR, Friedman LC, Rubinstein WS, et al. Effect of a computer-based decision aid on knowledge, perceptions, and intentions about genetic testing for breast cancer susceptibility: a randomized controlled trial. JAMA. 2004;292(4):442-52.

48. Ozuah PO, Reznik M. Residents' asthma communication skills in announced versus unannounced standardized patient exercises. Ambul Pediatr. 2007;7(6):445-8. 